\title{
The influence of pre-hospital medication administration in ST-elevation myocardial infarction patients on left ventricular ejection fraction and intra-hospital death
}

\author{
Magdalena Żurowska-Wolak, Michał Owsiak², Stanisław Bartuśs ${ }^{3}$ Marcin Mikos ${ }^{4}$ \\ ${ }^{1}$ Division of Emergency Medical Services, Faculty of Health Sciences, Jagiellonian University Medical College, Krakow, Poland \\ ${ }^{2}$ Department of Cardiology, Dietl's Hospital, Krakow, Poland \\ ${ }^{3}$ Department of Interventional Cardiology, Faculty of Medicine, Jagiellonian University Medical College, Krakow, Poland \\ ${ }^{4}$ Department of Bioinformatics and Public Health, Faculty of Medicine and Health Sciences, Andrzej Frycz Modrzewski Krakow University, \\ Krakow, Poland
}

Adv Interv Cardiol 2021; 17, 1 (63): 39-45

DOI: https://doi.org/10.5114/aic.2021.104766

\begin{abstract}
A bstract
Introduction: Currently, invasive cardiology techniques are the preferred method of treatment for patients with ST-elevation myocardial infarction (STEMI). Improving the care of patients with STEMI is possible by minimizing the time that elapses from the onset of pain to the start of treatment. As studies indicate, early pharmacotherapy, especially with antiplatelet and anticoagulant medications, allows for their early effectiveness.

Aim: To assess the influence of early administration of antiplatelet (clopidogrel) and anticoagulant medications in the pre-hospital period in patients with ST-elevated myocardial infarction on the frequency of in-hospital deaths and on the left ventricular ejection fraction evaluated at hospital discharge.

Material and methods: In this study, a retrospective analysis of 573 patients hospitalized due to ST-segment elevation myocardial infarction in one of Krakow's hospitals from January 2011 to December 2015 (excluding the whole of 2013) was used as a research method.

Results: As many as $97 \%$ of patients received pre-hospital pharmacotherapy, but only $46.0 \%$ of respondents received unfractionated heparin, and $19.2 \%$ received clopidogrel. The in-hospital mortality rate was $6.7 \%$, but among patients prehospitally treated with clopidogrel and unfractionated heparin, the in-hospital mortality rate was $1.1 \%$. Prehospital administration of clopidogrel significantly decreased the possibility of reduced left ventricular ejection fraction $(\mathrm{OR}=0.27 ; 95 \% \mathrm{Cl}$ : 0.09-0.90).

Conclusions: Among pre-hospital procedures, only administration of a second antiplatelet drug (clopidogrel) significantly decreased the risk of reduced left ventricular ejection fraction, and administration of clopidogrel or heparin, or a combination of both, significantly decreased the risk of in-hospital death in patients with STEMI.
\end{abstract} fraction.

Key words: pre-hospital pharmacotherapy, ST-elevation myocardial infarction, in-hospital prognosis, left ventricular ejection

\section{Su m m a ry}

Invasive cardiology techniques are the preferred method of treatment for patients with ST-elevation myocardial infarction. Improving the care of patients with ST-elevation myocardial infarction is possible by minimizing the time between the onset of pain and the start of treatment. As studies indicate, early pharmacotherapy, especially with antiplatelet and anticoagulant medications, allows for their early effectiveness. The aim of the study was to assess the influence of early administration of a second antiplatelet and anticoagulant medications in the pre-hospital period in patients with ST-elevated myocardial infarction on the frequency of in-hospital deaths and left ventricular ejection fraction evaluated at discharge.

\section{Corresponding author:}

Marcin Mikos, Department of Bioinformatics and Public Health, Faculty of Medicine and Health Sciences, Andrzej Frycz Modrzewski Krakow University, Krakow, Poland, e-mail: m.mikos@dietl.krakow.pl

Received: 23.09.2020, accepted: 30.12.2020. 


\section{Introduction}

Cardiovascular diseases are among the main causes of death in Poland and worldwide. Of them, ischemic heart disease, including myocardial infarction, accounts for a significant percentage [1]. Currently, invasive cardiology techniques are the preferred method of treatment in patients with ST-segment elevation myocardial infarction (STEMI). Early pharmacotherapy, especially involving antiplatelet and anticoagulant drugs, is an important part of the treatment of patients with acute coronary syndromes (ACS). For many years, the MONA regimen including administration of morphine, oxygen, nitroglycerin and aspirin was the standard pre-hospital treatment of STEMI patients, and after the introduction of common access to mechanical reperfusion, it additionally included administration of a clopidogrel loading dose and a bolus of unfractionated heparin. The new antiplatelet drugs (prasugrel, ticagrelor) have modified the standard pre-hospital pharmacotherapy, which nowadays aims at individual assessment of each patient and the provision of appropriate treatment rather than administration of a routine set of medications. Based on the studies conducted so far, many of the pre-hospital drugs do not affect the prognosis of patients with ST-segment elevation myocardial infarction. Morphine has no effect on the annual mortality rate in patients with STEMI [2], and a high concentration of oxygen in patients with uncomplicated myocardial infarction may be harmful [3]. Nitroglycerin is used to control the pain symptoms; however, it should not be routinely applied in patients with STEMI [4]. On the other hand, acetylsalicylic acid (ASA), the basic antiplatelet drug, reduces mortality; therefore it should be administered as early as possible $[4,5]$. ESC guidelines recommend the administration of an anticoagulant (unfractionated heparin, enoxaparin or bivalirudin) [4]. Unfractionated heparin (UFH) is easily available in Polish pre-hospital conditions; its additional advantage is the reversibility of the therapeutic effect after using protamine sulphate [4]. In pre-hospital treatment, the second antiplatelet medication from the P2Y12 inhibitor group is a standard. Until recently, clopidogrel has been routinely administered in a loading dose, but, as it has been proved, both prasugrel and ticagrelor allow clinical benefits to be obtained as compared to clopidogrel in patients with acute coronary syndromes, and they are currently recommended as preferred drugs $[6,7]$. The strategy of early pre-hospital administration of these medications compared to perioperative administration remains an open question, as the results of previous studies did not allow the strategy of pre-hospital administration of prasugrel and ticagrelor to be included in the current recommendations [8].

The administration of prasugrel before coronarography is not recommended [5]. The improvement of care of patients with STEMI is possible due to minimization of the time from the onset of pain to the start of treatment. As studies indicate, early pharmacotherapy, especially including antiplatelet and anticoagulant medications, in a patient with infarction allows for their early efficacy [9]. At the time of the research, pre-hospital administration of clopidogrel was a model which was commonly used in Poland [10]. However, not all emergency medical teams (EMTs) could carry it out (depending on the type of EMT and its equipment), and the type of treatment applied could affect the treatment effect and survival of patients with STEMI [10].

\section{Aim}

The aim of the present study is to assess the influence of early administration of antiplatelet and anticoagulant medications by emergency medical teams in patients with STEMI on the frequency of in-hospital deaths as well as on the left ventricular ejection fraction assessed at discharge.

\section{Material and methods}

In the study, a retrospective analysis of medical records (hospital records, medical card specifying rescue procedures performed by an emergency medical team) was used as a research method. The study included patients of the Krakow Centre of Invasive Cardiology, Electrotherapy and Angiology brought by EMTs from the place where they fell ill from January 2011 to December 2015 (excluding the whole of 2013, when organizational changes were introduced in the medical rescue teams, which had an influence on lower quality and the incompleteness of data available in medical records). Ethical approval for this study was obtained (122/6120/185/2015)

\section{Inclusion and exclusion criteria}

All patients who were transported to hospital with a diagnosis of myocardial infarction (534 patients) or other (62 patients), but in whom ST-segment elevation myocardial infarction was finally diagnosed, were selected for further analysis. Of the 596 patients with STEMI brought by the emergency medical teams, 573 patients were included for further analysis, in the case of whom data on the ambulance travel time to the incident site were obtained. Patients sent from other hospitals, patients in the case of whom data on the ambulance travel time of a medical rescue team to the incident site were not available and patients treated in 2013 were excluded from further analysis. There were no other exclusion criteria.

\section{Statistical analysis}

Statistical analyses were performed using Statistica 10.0 (StatSoft, Inc. Statistica software, version 10.0) and IBM SPSS software version 23. For continuous variables, 
the mean value and standard deviation (SD), minimum and maximum were determined. For qualitative variables, the absolute and percentage number of cases in relation to the whole analyzed group are presented. The nonparametric Mann-Whitney $U$ test was used to compare two samples. When comparing more samples, the nonparametric Kruskal-Wallis test was used. The Shapiro-Wilk test was used to assess the normality of the distribution. The chi-square test $\left(\chi^{2}\right)$ was used to analyze the relationship of qualitative variables. The Pearson correlation coefficient or Spearman's rank correlation coefficient was used to analyze the relationship between continuous variables. The value $\alpha=0.05$ was set as the level of statistical significance. In addition, univariate logistic regression as well as multivariate regression allowing for the influence of more than one variable was used to investigate how the analyzed features were related to hospital death and reduced left ventricular contractility. A series of independent logistic regression models (for each prehospital procedure separately) were performed to include variables which are significantly associated with the dependent variable, and to account for the recognized confounding factors. The results included four models: 1 - one-dimensional (raw), 2 - taking into account the influence of age and gender, 3 - model 2 and the analyzed time and distance, model 4 - model 3 and risk factors (hypercholesterolemia, hypertension, diabetes, kidney function) and the occurrence of a shock. The results are presented as the odds ratio with a 95\% confidence interval.

\section{Results}

\section{Characteristics of the studied population}

Most of the patients were men ( $n=375 ; 65.4 \%)$. The mean age was $64.4 \pm 11.8$ years (minimum 35 , maximum $102)$. The mean age of women was $69.5 \pm 12.2$ years, and of men $61.5 \pm 10.6$ years $(p<0.01)$. Hypertension occurred in $69.2 \%$ of patients $(n=395) .19 .0 \%$ of patients ( $n=109)$ had diabetes. During hospitalization, diabetes was diagnosed in 42 (7.3\%) patients. In total, diabetes was present in $26.4 \%$ of patients $(n=151)$. The mean age was $64.4 \pm 11.8$ years occurred in $60.6 \%$ of patients $(n=347)$. During hospitalization, hypercholesterolemia was additionally diagnosed in 120 (20.9\%) patients. In total, hypercholesterolemia was present in $81.5 \%$ of patients $(n=467)$. Chronic renal failure occurred in $2(3 \%)$ of patients. During hospitalization, based on the test results, chronic renal failure was diagnosed in a total of $10.1 \%$ of patients $(n=58)$. There is no known history of patients regarding previous myocardial infarction, percutaneous coronary interventions or coronary bypass surgery.

The vast majority of patients received pre-hospital pharmacotherapy ( $n=556 ; 97.0 \%)$. The MONA regimen was applied in full in $9.2 \%$ of patients $(n=53)$. In ad- dition, $49.2 \%$ of patients received morphine $(n=282)$, $61.0 \%$ oxygen $(n=350), 22.8 \%$ nitroglycerin $(n=131)$, and $84.6 \%$ acetylsalicylic acid $(n=485)$. Heparin was administered to $46.0 \%$ of subjects $(n=264)$, and clopidogrel to $19.2 \%(n=110)$. These results can be explained by the fact that $45.2 \%$ of patients in this study were transported by basic medical emergency teams, which did not have heparin or clopidogrel available then and could not administer it in accordance with the law in force at that time. The use of two antiplatelet drugs is very rare in the material tested. If patients were not given pre-hospital antiplatelet or anticoagulant medication, they received these drugs upon admission to hospital. The exact timing of the administration of antiplatelet and anticoagulants prior to coronary angioplasty has not been recorded in the medical records and cannot be determined. It seems important to indicate the time from the first medical contact (FMC), calculated from the arrival of the emergency medical team at the scene of the incident to the performance of percutaneous coronary angioplasty, which was $87 \pm 29(74-103) \mathrm{min}$.

The influence of medication administration on left ventricular ejection fraction

Echocardiographic assessment of left ventricular ejection fraction (LVEF) was performed in the hospital in $552(96.3 \%)$ patients. It was evaluated at the day of discharge. A comparison of the distribution of the examined factors between subjects with normal left ventricular ejection fraction (LVEF $\geq 55 \%$ ) and those whose LVEF was reduced (LVEF $<55 \%$ ) is shown in Table I.

It was found that among pre-hospital procedures only the administration of a second antiplatelet drug (clopidogrel) significantly affects left ventricular systolic function. In the multidimensional model, the use of clopidogrel considerably decreased the risk of occurrence of reduced left ventricular ejection fraction $(O R=0.27$; 95\% Cl: 0.09-0.90), as shown in Table II.

\section{The influence of medication administration on in-hospital death}

In total, 38 people out of 573 subjects died in the hospital (6.7\%). In-hospital deaths occurred most frequently on day 1 of hospitalization (52.6\%). Fifty-six patients did not receive any of the medications in the pre-hospital setting (aspirin, clopidogrel, heparin). Of this group, 9 patients died while in hospital.

The comparison of the distribution of examined factors between patients who died in hospital and those discharged from hospital is presented in Table III.

Before hospitalization, hypercholesterolemia was diagnosed in $60.6 \%$ of patients $(n=347)$. During hospitalization, lipid metabolism disorders were additionally diagnosed in 120 (20.9\%) patients. In total, hypercholesterolemia was present in $81.5 \%$ of patients $(n=467)$. 
Table I. Comparison of dichotomous variables between individuals with normal $(\geq 55 \%)$ and reduced $(<55 \%)$ left ventricle ejection fraction (LVEF)

\begin{tabular}{|c|c|c|c|c|c|c|}
\hline \multirow[t]{3}{*}{ Variable } & & \multicolumn{4}{|c|}{ LVEF } & \multirow[t]{3}{*}{$P$-value } \\
\hline & & \multicolumn{2}{|c|}{$\geq 55 \%$} & \multicolumn{2}{|c|}{$<55 \%$} & \\
\hline & & $n$ & $\%$ & $n$ & $\%$ & \\
\hline \multirow{4}{*}{$\begin{array}{l}\text { Antiplatelet and/or } \\
\text { anticoagulant medications }\end{array}$} & No medications & 32 & 11.6 & 244 & 88.4 & 0.06 \\
\hline & Heparin + clopidogrel & 16 & 18.0 & 73 & 82.0 & \\
\hline & Heparin & 20 & 12.0 & 147 & 88.0 & \\
\hline & Clopidogrel & 6 & 30.0 & 14 & 70.0 & \\
\hline \multirow[t]{2}{*}{ MONA regimen } & No & 71 & 14.2 & 428 & 85.8 & 0.08 \\
\hline & Yes & 3 & 5.7 & 50 & 94.3 & \\
\hline \multirow[t]{2}{*}{ Sex } & Female & 29 & 15.5 & 158 & 84.5 & 0.3 \\
\hline & Male & 45 & 12.3 & 320 & 87.7 & \\
\hline \multirow[t]{2}{*}{ Shock } & No & 67 & 14.0 & 413 & 86.0 & 0.3 \\
\hline & Yes & 7 & 9.7 & 65 & 90.3 & \\
\hline \multirow[t]{2}{*}{ Diabetes } & No & 61 & 15.0 & 347 & 85.0 & 0.07 \\
\hline & Yes & 13 & 9.0 & 131 & 91.0 & \\
\hline \multirow[t]{2}{*}{ Hypercholesterolemia } & No & 15 & 15.8 & 80 & 84.2 & 0.4 \\
\hline & Yes & 58 & 12.7 & 398 & 87.3 & \\
\hline \multirow[t]{2}{*}{ Hypertension } & No & 25 & 14.9 & 143 & 85.1 & 0.5 \\
\hline & Yes & 49 & 12.8 & 335 & 87.2 & \\
\hline \multirow[t]{2}{*}{ Renal failure } & No & 72 & 14.3 & 430 & 85.7 & 0.043 \\
\hline & Yes & 2 & 4.0 & 48 & 96.0 & \\
\hline
\end{tabular}

Table II. Relationship between occurrence of reduced maximal left ventricular ejection fraction and medication administration - one-dimensional and multidimensional models

\begin{tabular}{|c|c|c|c|c|c|c|c|c|c|c|c|c|c|}
\hline Variable & \multirow[b]{2}{*}{ No } & \multirow{2}{*}{$\frac{\mathrm{OR}^{\mathrm{A}}}{1}$} & \multicolumn{2}{|c|}{$95 \% \mathrm{Cl}$} & \multirow{2}{*}{$\frac{\mathrm{OR}^{\mathrm{B}}}{1}$} & \multicolumn{2}{|c|}{$95 \% \mathrm{Cl}$} & \multirow{2}{*}{$\frac{\mathrm{OR}^{\mathrm{C}}}{1}$} & \multicolumn{2}{|c|}{$95 \% \mathrm{Cl}$} & \multirow{2}{*}{$\frac{\mathrm{OR}^{\mathrm{D}}}{1}$} & \multicolumn{2}{|c|}{$95 \% \mathrm{Cl}$} \\
\hline Medications & & & & & & & & & & & & & \\
\hline & Heparin & 0.96 & 0.53 & 1.75 & 0.97 & 0.54 & 1.76 & 0.89 & 0.47 & 1.67 & 0.89 & 0.48 & 1.64 \\
\hline & Clopidogrel & 0.31 & 0.11 & 0.85 & 0.33 & 0.12 & 0.93 & 0.28 & 0.095 & 0.83 & 0.27 & 0.09 & 0.80 \\
\hline & Both & 0.60 & 0.31 & 1.15 & 0.59 & 0.31 & 1.15 & 0.42 & 0.21 & 0.84 & 0.52 & 0.25 & 1.06 \\
\hline Distance & & & & & & & & 1.03 & 0.99 & 1.05 & 1.03 & 0.99 & 1.05 \\
\hline Time to $\mathrm{PCl}$ & & & & & & & & 1.001 & 0.999 & 1.003 & 1.01 & 0.995 & 1.02 \\
\hline \multirow[t]{2}{*}{ MONA } & No & 1 & & & 1 & & & 1 & & & 1 & & \\
\hline & Yes & 2.76 & 0.84 & 9.10 & 2.89 & 0.87 & 9.57 & 2.83 & 0.85 & 9.43 & 2.91 & 0.87 & 9.74 \\
\hline Distance & & & & & & & & 1.02 & 0.999 & 1.05 & 1.02 & 0.998 & 1.05 \\
\hline Time to $\mathrm{PCl}$ & & & & & & & & 1.01 & 0.996 & 1.02 & 1.01 & 0.996 & 1.02 \\
\hline
\end{tabular}

$O R$-odds ratio, ${ }^{A}$ model $1=$ raw data, ${ }^{B}$ model $2=$ model $1+$ age + sex, ${ }^{C}$ model $3=$ model $1=2+$ age + sex + distance + time to PCl, ${ }^{D}$ model $4=$ model $2+$ diabetes + hypertension + hypercholesterolemia + renal failure + shock.

Based on the available data, it was not possible to establish why the mortality rate was higher in the group without diagnosed hypercholesterolemia, compared to the group with hypercholesterolemia (15.5\% vs. $4.3 \%$ ).

It was found that among procedures performed in a pre-hospital setting only the administration of anti- platelet and anticoagulant medications significantly affects the frequency of in-hospital death. Administration of clopidogrel or heparin or a combination of both significantly reduced the risk of in-hospital death in patients with STEMI (OR $=0.32 ; 95 \% \mathrm{Cl}$ : 0.13-0.78), as shown in Table IV. 
Table III. Comparison of dichotomous variables between patients who died in hospital and those who were discharged from hospital

\begin{tabular}{|c|c|c|c|c|c|c|}
\hline \multirow[t]{3}{*}{ Variable } & & \multicolumn{4}{|c|}{ Death } & \multirow[t]{3}{*}{$P$-value } \\
\hline & & \multicolumn{2}{|c|}{ No } & \multicolumn{2}{|c|}{ Yes } & \\
\hline & & $n$ & $\%$ & $n$ & $\%$ & \\
\hline \multirow{4}{*}{$\begin{array}{l}\text { Antiplatelet and/or } \\
\text { anticoagulant drugs }\end{array}$} & No medications & 264 & 91.7 & 24 & 8.3 & 0.08 \\
\hline & Heparin + clopidogrel & 88 & 98.9 & 1 & 1.1 & \\
\hline & Heparin & 163 & 93.1 & 12 & 6.9 & \\
\hline & Clopidogrel & 20 & 95.2 & 1 & 4.8 & \\
\hline \multirow[t]{2}{*}{ MONA regimen } & No & 484 & 93.1 & 36 & 6.9 & 0.4 \\
\hline & Yes & 51 & 96.2 & 2 & 3.8 & \\
\hline \multirow[t]{2}{*}{ Sex } & Female & 176 & 88.9 & 22 & 11.1 & 0.002 \\
\hline & Male & 359 & 95.7 & 16 & 4.3 & \\
\hline \multirow[t]{2}{*}{ Shock } & No & 471 & 96.1 & 19 & 3.9 & 0.001 \\
\hline & Yes & 64 & 77.1 & 19 & 22.9 & \\
\hline \multirow[t]{2}{*}{ Diabetes } & No & 399 & 95.0 & 21 & 5.0 & 0.03 \\
\hline & Yes & 136 & 90.1 & 15 & 9.9 & \\
\hline \multirow[t]{2}{*}{ Hypertension } & No & 162 & 92.0 & 14 & 8.0 & 0.3 \\
\hline & Yes & 373 & 94.4 & 22 & 5.6 & \\
\hline \multirow[t]{2}{*}{ Hypercholesterolemia } & No & 87 & 84.5 & 16 & 15.5 & $<0.001$ \\
\hline & Yes & 447 & 95.7 & 20 & 4.3 & \\
\hline \multirow[t]{2}{*}{ Kidney disfunction } & No & 494 & 95.9 & 21 & 4.1 & $<0.001$ \\
\hline & Yes & 41 & 70.7 & 17 & 29.3 & \\
\hline
\end{tabular}

Table IV. Relationship between occurrence of in-hospital death and performance of pre-hospital procedures one- and multidimensional models

\begin{tabular}{|c|c|c|c|c|c|c|c|c|c|c|c|c|c|}
\hline \multicolumn{2}{|l|}{ Variable } & \multirow{2}{*}{$\frac{\mathrm{OR}^{\mathrm{A}}}{1}$} & \multicolumn{2}{|c|}{$95 \% \mathrm{Cl}$} & \multirow{2}{*}{$\frac{\mathrm{OR}^{\mathrm{B}}}{1}$} & \multicolumn{2}{|c|}{$95 \% \mathrm{Cl}$} & \multirow{2}{*}{$\frac{\mathrm{OR}^{\mathrm{c}}}{1,00}$} & \multicolumn{2}{|c|}{$95 \% \mathrm{Cl}$} & \multirow{2}{*}{$\frac{\mathrm{OR}^{\mathrm{D}}}{1,00}$} & \multicolumn{2}{|c|}{$95 \% \mathrm{Cl}$} \\
\hline Medications & No & & & & & & & & & & & & \\
\hline & $\overline{\text { Yes }}$ & 0.66 & 0.35 & 1.26 & 0.55 & 0.28 & 1.10 & 0.47 & 0.22 & 1.00 & 0.32 & 0.13 & 0.78 \\
\hline Distance & & & & & & & & 0.98 & 0.95 & 1.01 & 0.97 & 0.94 & 1.01 \\
\hline Time to $\mathrm{PCl}$ & & & & & & & & 1.01 & 1.001 & 1.02 & 1.01 & 0.997 & 1.02 \\
\hline \multirow[t]{2}{*}{ MONA regimen } & No & 1 & & & 1 & & & 1 & & & 1 & & \\
\hline & Yes & 0.55 & 0.13 & 2.35 & 0.72 & 0.16 & 3.13 & 0.81 & 0.18 & 3.56 & 1.26 & 0.26 & 6.03 \\
\hline Distance & & & & & & & & 0.98 & 0.95 & 1.005 & 0.97 & 0.94 & 1.01 \\
\hline Time to $\mathrm{PCl}$ & & & & & & & & 1.01 & 1.001 & 1.02 & 1.01 & 0.997 & 1.02 \\
\hline
\end{tabular}

OR - odds ratio, ${ }^{A}$ model $1=$ one-dimensional model, ${ }^{B}$ model $2=$ model $1+$ age + sex, ${ }^{C}$ model $3=$ model $2+$ distance + time to PCl, ${ }^{D}$ model $4=$ model $2+$ diabetes + hypertension + hypercholesterolemia + renal failure + shock.

\section{Limitations of the study}

A limitation of this study is the fact that it is of an observational nature and is a registry study with retrospective data obtained from information contained in medical records. Therefore, it was not possible to verify the data contained therein, such as the observed differences in reporting the same time by emergency medical teams and the hemodynamics laboratory. Additionally, in the long follow-up period (from 2010 to 2015), patients' treatment in terms of hospital procedures may have changed, which has not been included in this analysis.

\section{Discussion}

Early pharmacotherapy in myocardial infarction, especially involving antiplatelet and anticoagulant medications in a patient with myocardial infarction, allows 
for their early efficacy. Most studies argue for pre-hospital administration of clopidogrel in the case of STEMI, which has a positive effect on in-hospital mortality, but the value of early administration of this medication is not clearly confirmed due to limited data from clinical research on this strategy. In our study we observed a lower percentage of in-hospital deaths (1.1\%) among patients to whom clopidogrel and heparin were administered prehospitally, as compared to those who did not receive these medications $(8.3 \%)$ or who received heparin alone $(6.9 \%)$ or clopidogrel alone $(4.8 \%)(p=0.08)$.

In the multidimensional model, administration of heparin and/or clopidogrel significantly decreased the risk of in-hospital death ( $\mathrm{OR}=0.32 ; 95 \% \mathrm{Cl}$ : 0.13-0.78). However, no significant difference was observed after discharge. A reduction in in-hospital mortality in patients who received clopidogrel before arrival at the hemodynamics laboratory was also observed in the analysis of 5,955 patients from the Austrian register of acute coronary syndromes $(3.4 \%$ vs. $6.1 \%, p<0.01)$ [11]. In contrast, in Minneapolis (the U.S.), in a group of 2,014 patients with STEMI, no significant decline in in-hospital mortality $(2.8 \%$ vs. $3.2 \%, p=0.66)$ or 1 -year mortality (5.4\% vs. $6.1 \%, p=0.59)$ was found in the group of patients to whom clopidogrel had been previously administered [12].

Similarly, in the Netherlands, in a group of 1,365 patients who were given clopidogrel in an ambulance compared to 1,110 patients who were given clopidogrel in hospital there was no difference in the percentage of deaths, this time in a 30-day and a 1-year follow-up (3.4\% vs. $3.2 \%, p=0.76$ and $6.1 \%$ vs. $5.9 \%, p=0.80$ ) [13]. Meanwhile, in a study by Polish authors, among 1,667 patients with STEMI who were given clopidogrel in the pre-hospital phase or during coronary angiography, non-significantly lower 1-year mortality was observed in the group of early administration of the medication (8.8\% vs. $12.2 \%, p=0.07$ ), which could not be confirmed after taking into account confounding factors [14].

Nevertheless, a Swedish registry study, which included 13,847 patients, showed a significant reduction in the risk of death in a 30-day follow-up $(\mathrm{HR}=0.70 ; 95 \% \mathrm{Cl}$ : $0.57-0.85)$ and a 1-year follow-up $(\mathrm{HR}=0.76 ; 95 \% \mathrm{Cl}$ : 0.64-0.90) after pre-hospital administration of clopidogrel in patients with STEMI treated with $\mathrm{PCI}$, compared to patients who did not receive this medication [15].

Similarly, in the randomized CIPAMI trial assessing the difference between early (pre-hospital) clopidogrel administration and its administration in hospital (after coronarography and before angioplasty), a lower number of deaths, fewer recurrences of myocardial infarction and fewer revascularization procedures during hospitalization were observed in the group of patients who received clopidogrel in an ambulance, but this result did not reach statistical significance ( $7.5 \%$ vs. $2.5 \%, p=0.06)$ [16].
The meta-analysis conducted by Nairooz et al., which comprised 16 studies involving 61,517 patients with infarction who received invasive treatment, also showed a reduction in 30-day follow-up mortality in the group of early clopidogrel administration ( $2.8 \%$ vs. $4.1 \%$, OR = $0.70 ; 95 \% \mathrm{Cl}: 0.58-0.85, p=0.0003)$ compared to perioperative administration [17].

It should be emphasized that in most of the cited studies [11-13, 15], all patients received heparin in addition to clopidogrel. Also in our study, the lowest number of in-hospital deaths was observed when these medications were administered together.

The analysis of patients in the APPOSITION III study (evaluating the usefulness of the implantation of self-expandable stents during primary $\mathrm{PCl}$ ) shows that in the Netherlands, in a group of 407 patients, $92 \%$ of them received ASA in the pre-hospital phase, $81 \%$ received clopidogrel, and $74 \%$ received heparin. In France, among 131 patients this percentage was as follows, respectively: $90 \%, 82 \%, 50 \%$ [18]. In Germany, in the group of 2,266 patients of emergency teams, as many as $96.2 \%$ received ASA, clopidogrel and heparin [19].

The use of heparin in the analyzed material is comparable to French data, but much lower than in the Netherlands and Germany. In the material studied, the use of the second antiplatelet drug, i.e. clopidogrel, is rare, especially against the background of the quoted studies. This result can be explained by the fact that $45.2 \%$ of patients in this study were transported by basic emergency teams, which were not equipped with heparin or clopidogrel at that time.

The study showed that among pre-hospital procedures only the administration of a second antiplatelet drug (clopidogrel) significantly affects left ventricular systolic function. In the multidimensional model, the use of clopidogrel considerably lowered the risk of developing a reduced left ventricular ejection fraction; among the procedures performed in the pre-hospital setting, only the administration of antiplatelet and anticoagulant medications significantly affects the frequency of death in hospital. Administration of clopidogrel or heparin, or a combination of both of these medications, significantly reduced the risk of in-hospital death in STEMI patients.

\section{Conflict of interest}

The authors declare no conflict of interest.

\section{References}

1. Cierniak-Piotrowska M, Marciniak G, Stańczak J. Statystyka zgonów i umieralności z powodu chorób układu krążenia. In: Zachorowalność i umieralność na choroby układu krążenia a sytuacja demograficzna Polski. Strzelecki Z, Szymborski J (eds.). Rządowa Rada Ludnościowa, Warszawa 2015; 46-81 [online]. [Retrieved 10.02.2017]. Available on the Internet: http://bip. stat.gov.pl/organizacja-statystyki-publicznej/rzadowa-rada-ludnosciowa/publikacje-rzadowej-rady-ludnosciowej 
2. Puymirat E, Lamhaut L, Bonnet N, et al. Correlates of pre-hospital morphine use in ST-elevation myocardial infarction patients and its association with in-hospital outcomes and long-term mortality: the FAST-MI (French Registry of Acute ST-elevation and non-ST-elevation Myocardial Infarction) programme. Eur Heart J 2016; 37: 1063-71.

3. Cabello JB, Burls A, Emparanza JI, et al. Oxygen therapy for acute myocardial infarction. Cochrane Database Syst Rev 2013; 8: CD007160.

4. 2017 ESC Guidelines for the management of acute myocardial infarction in patients presenting with ST-segment elevation: The Task Force for the management of acute myocardial infarction in patients presenting with ST-segment elevation of the European Society of Cardiology (ESC). Eur Heart J 2018; 39: 119-77.

5. Barbash I, Freimark D, Gottlieb S, et al. Outcome of myocardial infarction in patients treated with aspirin is enhanced by pre-hospital administration. Cardiology 2002; 98: 141-7.

6. Wiviott SD, Braunwald E, McCabe $\mathrm{CH}$, et al. Prasugrel versus clopidogrel in patients with acute coronary syndromes. N Engl J Med 2007; 357: 2001-15.

7. Wallentin L, Becker RC, Budaj A, et al. Ticagrelor versus clopidogrel in patients with acute coronary syndromes. N Engl J Med 2009; 361: 1045-57.

8. Montalescot G, Bolognese L, Dudek D, et al. Pretreatment with prasugrel in non-ST-segment elevation acute coronary syndromes. N Engl J Med 2013; 369: 999-1010.

9. Arntz HR, Bossaert LL. Danchin N, et al. Wstępne postępowanie w zespołach wieńcowych. In: Wytyczne resuscytacji 2010. Polska Rada Resuscytacji, Krakow 2010; 167-77.

10. Dudek D, Filipiak KJ, Stępińska J, et al. Nowy model optymalnego doustnego leczenia przeciwpłytkowego pacjentów z zawałem serca z uniesieniem odcinka ST w Polsce. Stanowisko Polskiego Towarzystwa Kardiologicznego. Kardiol Pol 2011; 69: 986-94.

11. Dörler J, Edlinger M, Alber HF, et al. Clopidogrel pre-treatment is associated with reduced in-hospital mortality in primary percutaneous coronary intervention for acute ST-elevation myocardial infarction. Eur Heart J 2011; 32: 2954-61.

12. Larson DM, Duval S, Sharkey SS, et al. Clopidogrel pretreatment in ST-elevation myocardial infarction patients transferred for percutaneous coronary intervention. Am Heart J 2010; 160: 202-7.

13. Postma S, Dambrink JH, Ottervanger JP, et al. Early ambulance initiation versus in-hospital initiation of high dose clopidogrel in ST-segment elevation myocardial infarction. Thromb Haemost 2014; 112: 606-13.

14. Rakowski T, Siudak Z, Dziewierz A, et al. Prehospital clopidogrel administration in patients with ST-segment elevation myocardial infarction treated with primary $\mathrm{PCl}$ : real-life experience from the multicenter NRDES Registry. I Invasive Cardiol 2016; 28: E56-8.

15. Koul S, Smith JG, Scherstén F, et al. Effect of upstream clopidogrel treatment in patients with ST-segment elevation myocardial infarction undergoing primary percutaneous coronary intervention. Eur Heart J 201; 32: 2989-97.

16. Zeymer U, Arntz HR, Mark B, et al. Efficacy and safety of a high loading dose of clopidogrel administered prehospitally to improve primary percutaneous coronary intervention in acute myocardial infarction: the randomized CIPAMI trial. Clin Res Cardiol 2012; 101: 305-12.

17. Nairooz R, Valgimigli M, Rochlani Y, et al. Meta-analysis of clopidogrel pretreatment in acute coronary syndrome patients undergoing invasive strategy. Int J Cardiol 2017; 229: 82-9.
18. Vos NS, Amoroso G, Grundeken MJ, et al. Pre-hospital management, procedural performance and outcomes for primary percutaneous coronary intervention in ST-elevation myocardial infarction in the Netherlands: insights from the Dutch cohort of the APPOSITION-III trial. Neth Heart J 2016; 24: 730-9.

19. Zeymer U, Arntz HR, Dirks B, et al. Reperfusion rate and inhospital mortality of patients with ST segment elevation myocardial infarction diagnosed already in the prehospital phase: results of the German Prehospital Myocardial Infarction Registry (PREMIR). Resuscitation 2009; 80: 402-6. 